\title{
Food security: its components and challenges
}

\section{Karyn Havas* and Mo Salman}

Animal Population Health Institute,

Department of Veterinary Medicine and Biomedical Sciences,

Colorado State University,

1601 Campus Delivery, Fort Collins, Colorado 80523-1601, USA

E-mail: Karyn.havas@colostate.edu

E-mail: m.d.salman@colostate.edu

*Corresponding author

\begin{abstract}
Food security relates directly to nutrition and health. Typically food security is thought of as being related to availability and access of foodstuffs. Yet, the threat to food security also lies with urbanisation, income disparity, overpopulation, ecosystem degradation, animal health, and food wholesomeness. Food wholesomeness is also an important aspect of nutrition. Wholesomeness is monitored via food safety and food defence programmes, making them critical components of a food security programme as well. This article discusses these interrelations and concepts for future scientific and humanitarian development programmes.
\end{abstract}

Keywords: food security; food safety; food defence; hunger; malnutrition; macronutrition; micronutrition; development; humanitarian assistance; climate change; sustainability; urbanisation; overpopulation.

Reference to this paper should be made as follows: Havas, K. and Salman, M. (2011) 'Food security: its components and challenges', Int. J. Food Safety, Nutrition and Public Health, Vol. 4, No. 1, pp.4-11.

Biographical notes: Karyn Havas received her BSc from Mary Washington College in 2001, Doctor of Veterinary Medicine from Cornell University in 2005 and is currently a doctoral candidate in Epidemiology at Colorado State University.

Mo Salman received his Veterinary degree from Baghdad University, and his Masters of Preventive Veterinary Medicine and $\mathrm{PhD}$ in Comparative Pathology from the University California-Davis in 1980 and 1983, respectively. He has been a Professor at Colorado State University since 1984.

\section{Introduction}

Food is our energy source and limited access to food impacts health in multiple ways. Approximately one billion individuals in the world lack adequate amounts of food to meet their nutritional needs and are malnourished (Barrett, 2010). Malnourished individuals are unable to consume adequate amounts of macronutrients and micronutrients. Macronutrients include protein, fat and caloric content (Michaelsen et al., 2009), and micronutrients are the essential minerals and vitamins (Benoist, 2007). The 
consequences to macronutrient malnutrition are poor immune response, stunted physical and mental growth, lethargy and emaciation (Stephenson et al. 2000; Merriam-Webster Medical Dictionary, 2010b; Merriam-Webster Medical Dictionary, 2010a). Malnutrition of micronutrients such as iron, vitamin A and iodine result in anaemia, decreased immune system function, cretinism, blindness and cognitive impairment (Stephenson et al., 2000).

Twenty countries in Africa, Asia, the Western Pacific and the Middle East account for four-fifths of global macro- and micronutrient malnutrition. In these areas approximately 3.5 million deaths occur per year in children under five, and the deaths are attributed to illness related to undernutrition (Horton, 2008; Black et al., 2008). The World Health Organization (WHO) map for "Children aged under-five stunted, 2000-2008" (World Health Organization, 2010) indicates that the countries where greater than $40 \%$ of their children experience nutrition-related growth-stunting are concentrated in Africa, South Asia and the South Pacific islands.

The purpose of this paper is to discuss the role of food security in the general health of humans and food-producing animals. Also discussed is the need for improving our preparations and approaches to food security.

\section{Definition of food security}

The 1996 World Food Summit defined food security as "a situation that exists when all people, at all times, have physical, social and economic access to sufficient, safe and nutritious foods that meets their dietary needs and food preferences for a healthy life." (Barrett, 2010) This definition incorporates several needs: availability of food, access to food, and for the food to be culturally appropriate. There are many factors in today's global environment that exacerbate food security. It is true, we live in an age where we are growing and producing more food than ever before. We have enough food to feed the world's population, but it is not distributed properly nor is all food culturally appropriate across the globe. Local food access differs dramatically and the greatest difference exists between developed and developing countries. The primary reason for this inequity is an income-related difference between these populations (Hazell and Wood, 2008). It must be stated though, that in every country of the world there is hunger, and this often falls along economic and social lines. The underprivileged - be it individuals or countries often have less.

\section{The food security milieu}

There are three areas of global concern that impact food security: overpopulation, climate change and urbanisation. Areas of the world with the highest birth rates and population, where demand often exceeds supply, also have the greatest levels of hunger and disease. Local ecosystems provide the resources a population needs for food production, health, environmental management and water. Examples include rangeland, fertile soil, nutrient cycling, and wildlife for hunting, among others. The local ecosystem has a certain carrying capacity, and once this is exceeded the ecosystem becomes stressed and begins to break down. This is defined as ecosystem vulnerability (Ericksen, 2008). The results 
can include over-farmed soils, denuded grazing lands and dried up or contaminated wells, all of which contribute to an underfed population.

Climate change is having an impact on various regions of the world. In Sub-Saharan Africa droughts are becoming more frequent and of a longer duration. The indigenous knowledge that developed to deal with less severe drought is no longer adequate. The lack of water and continued grazing stresses the ecosystem and causes its disintegration and a serious food security situation. The Borana tribe in Ethiopia, for instance, is currently undergoing this phenomenon (Homann et al., 2008; Solomon et al., 2007). As food sources become more limited, the lack of nutrition exacerbates health (Wakabi, 2006) by causing immune suppression and making the population more prone to illness. Increased disease puts a greater energy demand on the body and leads to a greater need for nutrients that are not available. This is a cycle of hunger and disease that reduces lifespan, productivity and the ability to improve one's position.

Urbanisation is also a contributor to food insecurity. Mega-cities, cities of ten million-plus inhabitants, are most commonly found in developing countries. In fact, three-quarters of urban dwellers live in low- and middle-income countries (Satterthwaite et al., 2010). The world economy has taken advantage of the low-cost labour in these countries and this has fuelled the rural-to-urban migration. Most manufacturing jobs are in the cities and as overpopulated and depleted lands fail to supply basic economic needs despite typically being able to still produce adequate sustenance, people turn to these urban jobs and opportunities. Thus far, rural farmers have kept up with the supply, but the economic access to foodstuffs by urban dwellers remains a problem. The need to feed these mega-cities and the complications associated with economic access to food is great. This was highlighted in 2007 and 2008 when rising oil prices led to food becoming unaffordable to city-dwellers across the globe (Satterthwaite et al., 2010).

Food security is not limited to humans and their environment; it is also related to a major source of their food, the animals. Therefore, we cannot ignore communicable animal disease in this scenario. Contagious animal diseases can decimate an animal population or greatly reduce their productiveness, and this affects food availability and access. Even if humans are not infected, they are often greatly affected by the disease. Any loss of animals is a loss of a protein source via milk, meat or blood, as well as a labour source to till fields and transport foodstuffs to markets. This was acutely felt during the Rinderpest outbreak in Africa in 1896, but is felt on a lesser scale during outbreaks even today (Schwabe, 1984). Even diseases that do not have a high case-fatality rate but have a high morbidity, such as foot and mouth disease, cause such a severe illness in the animal that their production is greatly reduced. This can impact the food supply. Avian influenza, specifically H5N1, ruined flocks throughout the Western Pacific and threatened food security (Basuno et al., 2010; Wakabi, 2006). In addition, zoonotic diseases put humans at risk when they consume these animals, as they often do despite the fact the animal is sick (ProMED-mail, 2008; ProMED-mail, 2009a; ProMED-mail, 2009b). This relates to food wholesomeness. Food insecurity, in terms of access and availability, may force populations to pursue other food sources, such as bush meat, potentially exposing them to other diseases. This has been the case with sudden acute respiratory syndrome, AIDS and other diseases (Wolfe et al., 2005). Food security at first glance appears to be primarily a supply related issue, but further examination reveals that it is a supply and quality, or wholesomeness, issue as well. 


\section{Beyond access and availability: food safety and defence}

Typically, food is thought to have a positive impact on health by providing energy and essential nutrients to living beings. Yet, food that has adequate calories and nutrients can be detrimental to health if its consumption leads to illness. These foodborne diseases illustrate why food security not only involves availability and access to food, but that the food must be wholesome as well. The global burden of foodborne illness is challenging to measure. Even the most developed countries with advanced surveillance systems grossly under-report cases of foodborne illnesses. Most typically manifest as a gastrointestinal illness, which has vague clinical signs. Typically the reporting of cases requires seeing a doctor and submitting a laboratory sample for diagnosis (World Health Organization, 2007). This is likely to be a rare event in developing countries even if the burden of foodborne illness is high.

Foodborne illnesses can be caused by contamination of food with microbes, parasites or chemicals or through the consumption of animals or products from animals ill with zoonotic diseases. Common zoonotics of global concern include salmonellosis, cysticercosis, brucellosis, bovine spongiform encephalopathy, and E. coli O157:H7 associated hemolytic-uremic syndrome, to name just a few. Compromised food safety is also a food security issue. The contamination of food or the infection of animals can be accidental, via natural courses of disease ecology, due to agricultural practices or due to a pre-meditated act where an individual or group hopes to cause illness in a population through food (Commission of the European Communities, 2000). Food defence more specifically addresses the intentional aspect of food contamination for the purpose of causing economic and bodily harm and food safety addresses accidental, natural, or production process contamination.

The purpose of food safety initiatives is to reduce the burden of foodborne diseases in a population. These initiatives address the handling of food items from farm to fork and typically focus on animal health, animal residues, pesticide residues, good agricultural practices, pasteurisation, slaughter procedures, harvest procedures, storage, transport, food preservatives and additives and preparation of food products. Concern for food safety has resulted in the development and implementation of multiple initiatives and organisations such as the European Food Safety Association, the US Food and Drug Administration, US Department of Agriculture's Food Safety and Inspections Service, the Codex Alimentarius, The World Organization for Animal Health Terrestrial Manuals, and the use of Hazard Analysis Critical Control Points to name just a few (Vieira and Traill, 2007). In addition, reporting groups such as the International Food Safety Authorities Network (INFOSAN), PulseNet at the CDC, and the Global Foodborne Infections Network (GFN) have developed. Thus, despite inconsistent data, foodborne disease is recognised as a threat to the availability of wholesome foodstuffs worldwide. The WHO furthers this point with their efforts to determine the global disease burden of foodborne illnesses (World Health Organization, 2007).

Food security is further endangered by terrorist threats of intentional food supply contamination. These threats are mitigated via Food defence systems. Intentional food contamination or infection of food-producing animals is not beyond the capability or morals of extremist groups. Examples include a salad bar intentionally contaminated with Salmonella spp. by a religious cult (Török et al., 1997); a Shigella outbreak due to the contamination of workplace pastries (Kloavic et al., 1997); and the contamination of 
200 pounds of ground beef with an insecticide whose main ingredient was nicotine by a disgruntled retail food store employee (Center for Disease Control, 2003). Since these small-scale intentional contaminations were already a recognised threat, the concept of larger more coordinated incidents by extremist organisations became a higher likelihood, especially in the face of bold terrorist attacks through the 1990s and the first decade of the 21 st century. This has required coordination of efforts beyond the food production system to address these intentional threats.

Many governments have been proactive to address the threat of foodborne illness as a bioterrorist attack. For example, in the USA in 2002 the Food and Drug Administration (FDA) implemented the Public Health Security and Bioterrorism Preparedness and Response Act. It recognised that the public health arena was vulnerable to bioterrorism, especially regarding foodstuffs (Food and Drug Administration, 2002). In 2005, the US Department of Agriculture (USDA), FDA, Department of Homeland Security (DHS) and the Federal Bureau of Investigation (FBI) developed the Strategic Partnership Program Agroterrorism Initiative (SPPA). The SPPA was developed to recognise weaknesses in the infrastructure, to identify early warnings and indicators of a bioterrorism event, and to develop mitigation plans (US Food and Drug Administration et al., 2005).

Clearly food security has multiple interrelated components including food availability, access, cultural appropriateness and wholesomeness. Any compromise of food defence and food safety reduces the availability of wholesome food. This can occur via disease or chemical contamination of plants and animals, which causes them to be removed from the food chain or become a cause of illness if consumed. Both an unsafe and/or inadequate food supply results in poor nutrition, decreased energy and a compromised immune system from the lack of needed micronutrients. These effects all make one more prone to disease. How can we, therefore, address nutrition and health within the realm of food security, including food safety and food defence?

\section{How can scientists and humanitarian specialists address food security?}

The first issues of food security are availability and accessibility. These are exacerbated by the overuse of resources and poor distribution due to income inequity or social disturbance. Encouraging growth in agricultural sectors that focus on locally consumed crops rather than export markets may stimulate an influx of rural and community-based development funds and create a national market. Such projects would need to be based on local structure, knowledge and priorities and operate within the capacity of the ecosystem. Education is also a key as it increases literacy, making it easier to standardise and implement programmes during development. In addition, the education of women has been shown to lead to a reduction in family size as well as a reduction in poverty, and this results in an improved nutritional status for the family (Mishra and Retherford, 2000; Lomperis, 1991; Tyer-Viola and Cesario, 2010). A combination of these efforts can reduce the stress on the environment and increase local food distribution and availability.

Food safety increases with knowledge and better infrastructure, but foodborne illness never disappears. However, several things can be done to mitigate this problem. Fortunately better nutrition decreases susceptibility to illness, so addressing availability and accessibility of food is an important task. Education on the identification of illness in animals, proper slaughtering, food storage, food handling, food preparation and threats from food can also help. Culturally appropriate education about food as a source of 
illness is necessary, and it needs to apply to the population's view of health and sickness. Proper food defence is even more problematic, as it deals with so many other issues beyond the food itself. These issues include extremist ideologies, poverty, inequality, protectionism of beliefs and principles as well as food sources, and the target population. Yet, making people aware of signs of illness in their livestock, setting up nationally or locally regulated testing schemes for their industrialised food products, and encouraging community awareness and vigilance will be the first steps.

None of this can occur at an international level, although it will need international support and expertise. It must be supported at the national and local levels of every country that becomes involved in addressing the challenge of food security. Political management of growing urban centres to reduce inequity and provide basic needs for the poor will also be critical to success. Plans must be adapted appropriately to each place according to their needs and desires while striving to meet standards that have proven effective, such as the sanitary and phyto-sanitary measures developed by the The World Organization for Animal Health and adopted by the World Trade Organization. The food system of a community must be studied and strengthened within the realms of availability, access, safety and defence. Food systems are socio-ecologic systems that enable human beings to provide appropriate nutrients from their environmental resources (Ericksen, 2008). It is evident that these socio-ecologic systems are tightly linked to many economic systems as well as evidenced by the role of the World Trade Organization discussed above.

Food security structures can be mirrored off of effective government animal health and food safety organisations such as those that exist in the USA, the European Union, Australia, Brazil or Japan, just to name a few. Components that have proven effective in other countries can be modified and utilised in another country that desires to address these food-related issues. The creation of mirror organisations may not be completely appropriate, and flexibility during the process will be critical. Addressing macronutrient and micronutrient deficiencies as well as animal management, food storage and preparation methods, which increase food security, will really only bring superficial results. The greater issues lie in the global population growth, industrial-based change such as globalisation, and environmental stewardship that will address sustainability and climate change.

In conclusion, food security is a multi-dimensional topic. It does not just address the availability of food, but it also addresses its cost, cultural appropriateness, the balanced nature of its protein, fat, carbohydrate and micro-nutrient make-up, its source and the production practices used to cultivate and harvest food products, as well as freedom from contamination after harvest. This relates to both animal and plant based foods and is an issue across the globe. Food must not only meet our macro- and micronutrient needs, but it also must not cause disease in those who consume it. Efforts to address these topics must take into consideration community-based approaches and well-rounded interventions.

\section{References}

Barrett, C.B. (2010) 'Measuring food insecurity', Science, Vol. 327, No. 5967, p.825.

Basuno, E., Yusdja, Y. and Ilham, N. (2010) 'Socio-economic impacts of avian influenza outbreaks on small-scale producers in Indonesia', Transboundary and Emerging Diseases, Vol. 57, No. 1, pp.7-10. 
Benoist, B.D. (2007) 'Preventing and controlling micronutrient deficiencies in populations affected by an emergency', Organization, N.F.H.A.D.W.H. (Ed.), available at http://www.who.int/nutrition/publications/micronutrients/WHO_WFP_UNICEFstatement.pdf, World Health Organization, Geneva, Switzerland.

Black, R.E., Allen, L.H., Bhutta, Z.A., Caulfield, L.E., Onis, M.D., Ezzati, M., Mathers, C. and Rivera, J. (2008) 'Maternal and child undernutrition: global and regional exposures and health consequences', The Lancet, Vol. 371, No. 9608, pp.243-260.

Center for Disease Control (2003) 'Nicotine poisoning after ingestion of contaminated ground beef - Michigan, 2003', Morbidity and Mortality Weekly Reports, Centers for Disease Control, Atlanta, Georgia.

Commission of the European Communities (2000) White Paper on Food Safety, Brussels.

Ericksen, P.J. (2008) 'What is the vulnerability of a food system to global environmental change?', Ecology and Society, Vol. 13, No. 2, p.14.

Food and Drug Administration (2002) 'New rules to protect the food supply: FDA actions on Bioterrorism Act of 2002 legislation', in Information, F.D.A.E.R.R. (Ed.), Food and Drug Administration, Washington, DC.

Hazell, P. and Wood, S. (2008) 'Drivers of change in global agriculture', Philosophical Transactions of the Royal Society B: Biological Sciences, Vol. 363, No. 1491, pp.495-515.

Homann, S., Rischkowsky, B., Steinbach, J., Kirk, M. and Mathias, E. (2008) 'Towards endogenous livestock development: Borana Pastoralists' responses to environmental and institutional change', Human Ecology, Vol. 36, No. 4, pp.503-520.

Horton, R. (2008) 'Maternal and child nutrition: an urgent opportunity', The Lancet, Vol. 371, No. 9608 , p.179.

Kloavic, S.A., Kimura, A., Simons, S.L., Slutsker, L., Barth, S. and Ce, H. (1997) 'An outbreak of Shigella dysenteriae Type 2 among laboratory workers due to intentional food contamination', Journal of the American Medical Association, Vol. 278, No. 5, pp.396-398.

Lomperis, A.T. (1991) 'Teaching mothers to read: evidence from Columbia on the key role of maternal education', The Journal of Developing Areas, Vol. 26, No. 1, pp.25-52.

Merriam-Webster Medical Dictionary (2010a) 'Kwashiorkor', Merriam-Webster, Springfield, MA.

Merriam-Webster Medical Dictionary (2010b) 'Marasmus', Merriam-Webster, Springfield, MA.

Michaelsen, K.F., Hoppe, C., Roos, N., Kaestel, P., Stougaard, M., Lauritzen, L., Molgaard, C., Girma, T. and Friis, H. (2009) 'Choice of foods and ingredients for moderately malnourished children 6 months to 5 years of age', Food and Nutrition Bulletin, Vol. 30, No. 3, pp.S343-S404.

Mishra, V. and Retherford, R. (2000) 'Women's education can improve child nutrition in India', National Family Health Survey Bulletin, No. 15, pp.1-4.

ProMed-mail (2008) Avian influenza, human (16): Indonesia, Viet Nam, 24 January 2008, ed.

ProMed-mail (2009a) Anthrax-India: (OR), 20 October 2009, ed.

ProMed-mail (2009b) Anthrax, Human, Livestock-Kenya, 24 December 2009, ed.

Satterthwaite, D., Mcgranahan, G. and Tacoli, C. (2010) 'Urbanization and its implication for food and farming', Philosophical Transactions of the Royal Society B: Biological Sciences, Vol. 365, pp.2809-2820.

Schwabe, C.W. (1984) Human Health Costs of Animal Disease: Veterinary Medicine and Human Health, 3rd ed., Williams \& Wilkins, Baltimore.

Solomon, T.B., Snyman, H.A. and Smit, G.N. (2007) 'Cattle-rangeland management practices and perceptions of pastoralists towards rangeland degradation in the Borana zone of southern Ethiopia', Journal of Environmental Management, Vol. 82, No. 4, pp.481-494.

Stephenson, L.S., Lathan, M.C. and Ottesen, E.A. (2000) 'Global malnutrition', Parasitology, Vol. 121, No. S1, pp.S5-S22. 
Török, T.J., Tauxe, R.V., Wise, R.P., Livengood, J.R., Sokolow, R. and Mauvais, S. et al. (1997) 'A large community outbreak of salmonellosis caused by intentional contamination of restaurant salad bars', Journal of the American Medical Association, Vol. 278, No. 5, pp.389-395.

Tyer-Viola, L.A. and Cesario, S.K. (2010) 'Addressing poverty, education, and gender equality to improve the health of women worldwide', Journal of Obstetric, Gynecologic and Neonatal Nursing, Vol. 39, No. 5, pp.580-589.

US Food and Drug Administration, Department of Homeland Security, US Department of Agriculture and Federal Bureau of Investigation (2005) Strategic Partnership Program Agroterrorism (SPPA) Initiative, Washington, DC.

Vieira, L.M. and Traill, W.B. (2007) 'The role of food standards in international trade: evidence from Brazilian beef exports to the EU market', Journal of International Development, Vol. 19, No. 6, pp.755-764.

Wakabi, W. (2006) 'WWorst drought in a decade' leaves Kenya crippled', The Lancet, Vol. 367, No. 9514, pp.891-892.

Wolfe, N.D., Daszak, P., Kilpatrick, A.M. and Burke, D.S. (2005) 'Bushmeat hunting, deforestation, and prediction of zoonotic disease emergence', Emerging Infectious Diseases, Vol. 11, No. 12, pp.1822-1827.

World Health Organization (2007) 'Consultation to develop a strategy to estimate the global burden of foodborne diseases: taking stock and charting the way forward', World Health Organization, Geneva, Switzerland.

World Health Organization (2010) 'Children under-five stunted (\%), 2000-2008', 7 January 2010 ed., World Health Organization, Geneva, Switzerland. 